Review Paper http://ajol.info/index.php/ijbcs http://indexmedicus.afro.who.int

\title{
Physiologie de l'immunité colostrale chez les porcins et facteurs de variation du rendement et de la qualité immunitaire du colostrum de la truie
}

\author{
Aristide Mahoutin AGBOKOUNOU ${ }^{1 *}$, Gbênangnon Serge AHOUNOU ${ }^{2}$, \\ Issaka YOUSSAO ABDOU KARIM ${ }^{2}$, Guy Apollinaire MENSAH ${ }^{3}$, \\ Bénoît KOUTINHOUIN ${ }^{2}$ et Jean-Luc HORNICK ${ }^{4}$
}

${ }^{1}$ Centre Béninois de la Recherche Scientifique et de l'Innovation, 03 BP 1665 Cotonou, République du Bénin.

${ }^{2}$ Département de Production et Santé animales, Ecole polytechnique d'Abomey-Calavi, 01 BP 2009, Cotonou, République du Bénin.

${ }^{3}$ Institut National des Recherches Agricoles du Bénin, Centre de Recherche d'Agonkanmey (CRA / INRAB), Abomey-Calavi, République du Bénin.

${ }^{4}$ Institut Vétérinaire Tropical, Département de Productions animales, Faculté de Médecine vétérinaire, Université de Liège, 20, Boulevard de Colonster, Bâtiment B43, 4000 Liège, Belgique.

*Auteur correspondant, E-mail : agbokounou@hotmail.com

\section{RESUME}

Chez les porcins comme chez d'autres mammifères, le colostrum apporte des substances nutritives et des facteurs immunitaires pour compenser l'immunité non transmise avant la naissance et le déficit énergétique avec lequel naissent les porcelets. Le colostrum est alors un aliment déterminant dans la survie du porcelet pendant les premières heures de sa vie et par conséquent un facteur important de la productivité de la truie. Le mécanisme de sa synthèse et du transfert de l'immunité au nouveau-né est complexe et mérite d'être bien cerné en vue d'assurer la survie du porcelet. La présente revue a non seulement décrit les mécanismes de synthèse des composants immunitaires et de leur transfert au nouveau-né, mais a fait aussi l'état des lieux de récents travaux sur les facteurs influençant la quantité et la qualité immunitaire du colostrum chez la truie. L'accent a été alors mis sur la composition du colostrum, la synthèse des composés nutritifs et immunitaires (transfert des immunoglobulines du sang dans la glande mammaire et leur synthèse locale), le transfert des immunoglobulines et des cellules immunitaires au porcelet et les facteurs endogènes et exogènes influençant la quantité et la qualité immunitaire du colostrum de la truie.

(C) 2017 International Formulae Group. All rights reserved.

Mots clés : Colostrum, immunité, espèce porcine, immunoglobuline. 


\title{
Physiology of colostral immunity and factors influencing yield and immune quality of sow colostrum
}

\begin{abstract}
In pigs as in other mammals, colostrum provides nutrients and immune factors to compensate the nontransmitted immunity before birth and the energy deficit with which piglets are born. Colostrum intake is then crucial for piglet survival during the first hours of life and therefore for sows productivity. The mechanism of its synthesis and immunity transfer to the newborn is complex and deserves to be well defined in order to ensure piglet survival. This review describes the synthesis mechanisms of immune components and their transfer to the newborn. It also provides an update of recent research on the factors influencing the quantity and immune quality of colostrum in sows. Emphasis was then placed on the colostrum composition, synthesis of nutrients and immune compounds (transfer of blood immunoglobulins in the mammary gland and their local synthesis), the transfer of immunoglobulins and immune cells in the piglet and endogenous and exogenous factors affecting the quantity and immune quality of colostrum from the sow.
\end{abstract}

(C) 2017 International Formulae Group. All rights reserved.

Keywords: Colostrum, immunity, swine, immunoglobulin.

\section{INTRODUCTION}

Chez l'espèce porcine, la placentation est de type épithéliochorial (Le Dividich, 2006 ; Hurley et Theil, 2011). Ce type de placentation ne permet pas le transfert des immunoglobulines maternelles vers le fœtus (Hlavova et al., 2014) et le porcelet naît alors sans protection immunitaire avec une disponibilité en énergie (glycogène et lipide) très inférieure à ses besoins (Le Dividich et al., 2005 ; Declerck et al., 2015). En effet, la disponibilité en énergie nette du porcelet et ses besoins sont estimés respectivement à 400 $\mathrm{kJ}$ et $900-950 \mathrm{~kJ}$ par kilogramme de poids à la naissance dans les 24 heures de vie (Le Dividich et al., 2005). A sa naissance, l'intestin du nouveau-né est colonisé par les bactéries de son environnement de vie et celles des flores vaginale et fécale de sa mère (Daudelin, 2009). Pour faire face à ces contraintes de survie dans les premières heures de la vie, le seul recours du porcelet est le colostrum. Le colostrum est alors un aliment déterminant dans la survie du porcelet pendant les premières heures de sa vie (Decaluwé et al., 2014). Cette survie est assurée à travers l'apport d'énergie, de facteurs immunitaires et de promoteurs de croissance (Salmon et al., 2009 ; Devillers et al., 2011 ; Quesnel, 2011a ; Declerck et al., 2015). En dehors de l'énergie, le colostrum transmet alors au porcelet une immunité systémique et locale et des facteurs qui assurent la maturité de son système immunitaire (Quesnel, 2011a) effectivement en place à la naissance, mais immature. Il jouit alors d'une immunité passive avant de commencer à synthétiser ses propres anticorps. L'immunité colostrale consiste alors en cette protection passive qui fait intervenir la synthèse des composants immunitaires du colostrum et l'absorption de ceux-ci par le nouveau-né. Cette forme d'immunité n'est adéquate que si l'animal ingère suffisamment de colostrum de bonne qualité et absorbe ses constituants immunitaires. Une consommation de colostrum de faible qualité immunitaire est la cause de diarrhée observée dans la première semaine de vie dans certains élevages (Gin, 2008). De plus, les porcelets consommant les plus fortes quantités de colostrum ont des concentrations sériques maximales d'anticorps (Le Dividich et al., 2005), celles-ci atteignant le plateau avec une consommation de colostrum de 200 à $250 \mathrm{~g}$ (Quesnel, 2011a). Dans ce contexte, toute intervention en vue d'optimiser l'immunité chez le nouveau-né 
nécessite alors la compréhension des mécanismes de production du colostrum, de synthèse et d'absorption de ses composants immunitaires. La présente synthèse a alors pour objectif de décrire le mécanisme de synthèse des composants du colostrum, le mécanisme de transfert de l'immunité colostrale aux porcelets et les facteurs de variation de la quantité et de la qualité immunitaire du colostrum de la truie.

\section{COMPOSITION DU COLOSTRUM ET SYNTHESE DE SES COMPOSANTS}

Le colostrum est un mélange de composés non seulement sécrétés dans la glande mammaire, mais aussi transférés du sérum sanguin vers cet organe, mélange qui assure la survie du nouveau-né pendant les premiers jours de sa vie à travers la fourniture de nutriments, de composés immunitaires et de facteurs de croissance. Le colostrum assure donc aux nouveau-nés trois fonctions essentielles : nutritionnelle, immunitaire et physiologique (Quesnel, 2011a). Le colostrum de la truie est constitué de composés nutritionnels et immunitaires puis de facteurs de croissance (Tableau 1).

Les composés nutritionnels sont les protéines, les lipides, le lactose, les minéraux et les vitamines. Les lipides et le lactose sont les principales sources d'énergie du colostrum. La teneur en énergie brute $\mathrm{du}$ colostrum est comprise entre 1,04 et 1,62 $\mathrm{kcal} / \mathrm{g}$ et augmente avec l'accroissement de sa teneur en lipide (Le Dividich et al., 1997).

Les composants immunitaires du colostrum sont constitués de trois groupes de facteurs immunitaires : les facteurs à immunité humorale représentés par les immunoglobulines (Ig), les facteurs à immunité cellulaire et les facteurs bioactifs.

- Les immunoglobulines ou anticorps sont les principales composantes $\mathrm{du}$ colostrum (Klobasa et al., 1987) et représentent 70 à $80 \%$ des protéines de cette sécrétion. Elles comprennent selon leurs propriétés biologique et physique cinq classes (Rouze, 1974) de protéines codées par les gènes Gamma (IgG), $\mathrm{Mu}(\operatorname{IgM})$, Alpha (IgA), Epsilon (IgE) et
Delta (IgD). L'IgM est la classe qui apparaît d'abord à l'exposition de l'organisme à un antigène pour la première fois (Hurley et Theil, 2011) et les autres isotypes d'Ig dérivent par adaptation de la molécule primitive d'IgM ancestrale (Salmon, 2011). Si les quatre autres Igs sont exprimées dans le colostrum de la truie, l'expression de la dernière $(\mathrm{IgD})$ est controversée (Butler et al., 2009). Les isotypes IgG et IgA prédominent respectivement dans le colostrum et le lait de la truie avec des concentrations respectives de 64 et 3,04 mg/ml (Le Dividich, 2006) alors que chez la vache c'est l'IgG1, l'une des sousclasses des IgGs, qui prédomine et dans le colostrum et dans le lait (Salmon, 1999). Les immunoglobulines sont caractérisées par la forte variation de leurs concentrations colostrales, variation qui peut s'observer entre truies d'un même élevage et d'une même bande (Le Dividich, 2006). Elle s'observe également dans le temps (Klobasa et al., 1987) (Figure 1).

- Les facteurs à immunité cellulaire retrouvés dans le colostrum et le lait de la truie sont les lymphocytes, les éosinophiles, les macrophages et les neutrophiles (Lee et al., 1983). On y trouve également de $2.10^{5}$ à $10^{7}$ cellules épithéliales par ml (Evans et al., 1982).

- Les facteurs bioactifs sont représentés par les antimicrobiens et les cytokines. Les antimicrobiens généralement retrouvés dans le colostrum de la truie sont la lactoferrine, la lactoperoxydase, le lysozyme, la transferrine et l'haptoglobine. Les cytokines souvent retrouvées dans le colostrum et le lait de la truie sont les interleukines 4, 6, 10 et 12 (IL-4, IL-6, IL-10 et IL-12), l'interféron ' (IFN$\Upsilon)$, le Transforming Growth Factor beta 1 (TGF- $\beta 1$ ) et le Tumor Necrosis Factor $\alpha$ (TNF- $\alpha$ ) (Nguyen et al., 2007).

Le troisième composant majeur du colostrum est représenté par les facteurs de croissance qui sont nombreux dans cette sécrétion. Les plus identifiés dans le colostrum et le lait de la truie sont l'Epidermal Growth Factor (EGF), 1'Insulin-like Growth Factors I et II (IGF-I, l'IGF-II), l'insuline et 
les Transforming Growth Factors $\beta 1$ et $\beta 2$ (TGF- $\beta 1$ et TGF- $\beta 2$ ) (Xu et al., 2002). Il apparait que le facteur bioactif TGF- $\beta 1$ qui est une cytokine joue également le rôle de facteur de croissance. D'une manière générale, les facteurs de croissance du colostrum et du lait, comme leur nom l'indique, stimulent la croissance et la différenciation des cellules chez les mammifères (Boudry, 2009). Ils augmentent alors la hauteur des villosités intestinales et la profondeur des cryptes chez les porcelets (Mei et al., 2006). Les promoteurs de croissance et particulièrement, les TGF- $\beta$ du colostrum peuvent réguler la fonction intestinale et jouer un rôle dans l'adaptation postnatale de l'intestin des porcs-nouveau-nés (Mei et al., 2006). L'absorption des facteurs de croissance est indépendante de l'âge du porcelet particulièrement pour les IGF-I (Xu et Wang, 1996).

Chez la truie comme chez d'autres mammifères, la lactogenèse est essentiellement la phase de synthèse du colostrum. La synthèse du colostrum par la truie commence en fin de gestation et avant la parturition et cette synthèse se poursuit jusqu'à 24 à 48 heures après le début de la lactation (Klobasa et al., 1987 ; Devillers et al., 2006). Les cellules épithéliales des acini de la glande mammaire sont au centre de cette synthèse et sont caractérisées par l'existence entre elles d'une structure particulière dénommée les jonctions serrées qui assurent l'étanchéité de l'épithélium mammaire et jouent un rôle important dans le mécanisme de synthèse des constituants du colostrum. Ces constituants parviennent dans la lumière des alvéoles par quatre différentes voies: l'exocytose, la sécrétion des gouttelettes lipidiques, le passage trans-cellulaire et le passage para-cellulaire (Devillers et al., 2006). L'exocytose est la principale voie de synthèse des protéines et du lactose. La voie transcellulaire est celle utilisée par les immunoglobulines et plusieurs facteurs de croissance et hormones pour atteindre la lumière alvéolaire après avoir traversé par exocytose la membrane cellulaire apicale des cellules épithéliales (Klopfenstein et al., 2002). Le passage para-cellulaire fait intervenir les jonctions serrées entre les cellules épithéliales. En effet, les cellules immunitaires, les immunoglobulines plasmatiques et les électrolytes parviennent dans la lumière alvéolaire en passant entre les cellules épithéliales à la faveur de l'ouverture en fin de gestation de ces jonctions (Klopfenstein et al., 2002 ).

Tableau 1: Composition du colostrum et du lait de la truie.

\begin{tabular}{|c|c|c|c|}
\hline Composants & Colostrum & Lait & Références \\
\hline \multicolumn{4}{|c|}{ Facteurs nutritionnels } \\
\hline Matière Sèche $(\%)$ & 25,6 & 18,4 & \multirow{4}{*}{ Klobasa et al., 1987} \\
\hline Protéine (\%) & 15,7 & 5,5 & \\
\hline Lipide (\%) & 5,0 & 6,5 & \\
\hline Lactose (\%) & 3,1 & 5,5 & \\
\hline Cendre (\%) & 0,66 & 0,80 & \multirow{9}{*}{ Csapó et al., 1996} \\
\hline Potassium (mg/kg) & 1100 & 836 & \\
\hline Sodium $(\mathrm{mg} / \mathrm{kg})$ & 685 & 470 & \\
\hline Calcium $(\mathrm{mg} / \mathrm{kg})$ & 686 & 1659 & \\
\hline Phosphore (mg/kg) & 1017 & 1202 & \\
\hline Magnésium (mg/kg) & 78,5 & 93,1 & \\
\hline Vitamine A (mg/kg) & 1,61 & 0,92 & \\
\hline Vitamine D3 (mg/kg) & 0,015 & 0,009 & \\
\hline Vitamine $E(\mathrm{mg} / \mathrm{kg})$ & 3,69 & 2,53 & \\
\hline
\end{tabular}




\begin{tabular}{|c|c|c|c|}
\hline \multirow{2}{*}{ Vitamine K3 (mg/kg) } & \multirow{2}{*}{0,092} & \multirow{2}{*}{0,089} & \\
\hline & & & \\
\hline Vitamine C(mg/kg) & 68,4 & 45,3 & \\
\hline \multicolumn{4}{|c|}{ Immunoglobulines } \\
\hline $\mathrm{IgG}(\mathrm{mg} / \mathrm{ml})$ & 63,27 & 0,41 & \multirow{3}{*}{ Leonard et al., 2010} \\
\hline $\operatorname{IgA}(\mathrm{mg} / \mathrm{ml})$ & 10,40 & 3,81 & \\
\hline $\operatorname{IgM}(\mathrm{mg} / \mathrm{ml})$ & 3,97 & 1,83 & \\
\hline \multicolumn{4}{|c|}{ Cellules immunitaires } \\
\hline Neutrophiles (\%) & 64,0 & 40,7 & \multirow{5}{*}{ Wuryastuti et al., 1993} \\
\hline Macrophages (\%) & 5,6 & 15,5 & \\
\hline Lymphocytes (\%) & 26,5 & 19,2 & \\
\hline Eosinophiles (\%) & 0,7 & 0,4 & \\
\hline Cellules épithéliales & 1,4 & 23,6 & \\
\hline \multicolumn{4}{|c|}{ Facteurs bioactifs } \\
\hline Lactoferrine $(\mathrm{mg} / \mathrm{ml})$ & 1,2 & 0,3 & Harada et al., 1999 \\
\hline Lactoperoxydase (g/l) & 0,02 & 0,03 & \multirow{2}{*}{ Geale, 2011} \\
\hline Lysozyme (g/l) & 0,0004 & 0,0004 & \\
\hline Haptoglobine $(\mathrm{mg} / \mathrm{ml})$ & 1,11 & 0,36 & Hiss-Pesch et al., 2011 \\
\hline IL-6 & $2,7 \mathrm{ng} / \mathrm{ml}$ & $550 \mathrm{pg} / \mathrm{ml}$ & \multirow{3}{*}{ Nguyen et al., 2007} \\
\hline TNF- $\alpha$ & $24 \mathrm{pg} / \mathrm{ml}$ & Non détectable & \\
\hline IL-10 & $157 \mathrm{pg} / \mathrm{ml}$ & $30 \mathrm{pg} / \mathrm{ml}$ & \\
\hline \multicolumn{4}{|c|}{ Promoteurs de croissance } \\
\hline EGF (ng/ml) & 1550 & $150-250$ & \multirow{5}{*}{ Xu et al., 2002} \\
\hline TGF- $\beta$ (ng/ml) & 78 & 6 & \\
\hline IGF-I (ng/ml) & 360 & 100 & \\
\hline Leptine (ng/ml) & 36 & 30 & \\
\hline Insuline $(\mu \mathrm{UI} / \mathrm{ml})$ & 400 & $25-60$ & \\
\hline
\end{tabular}

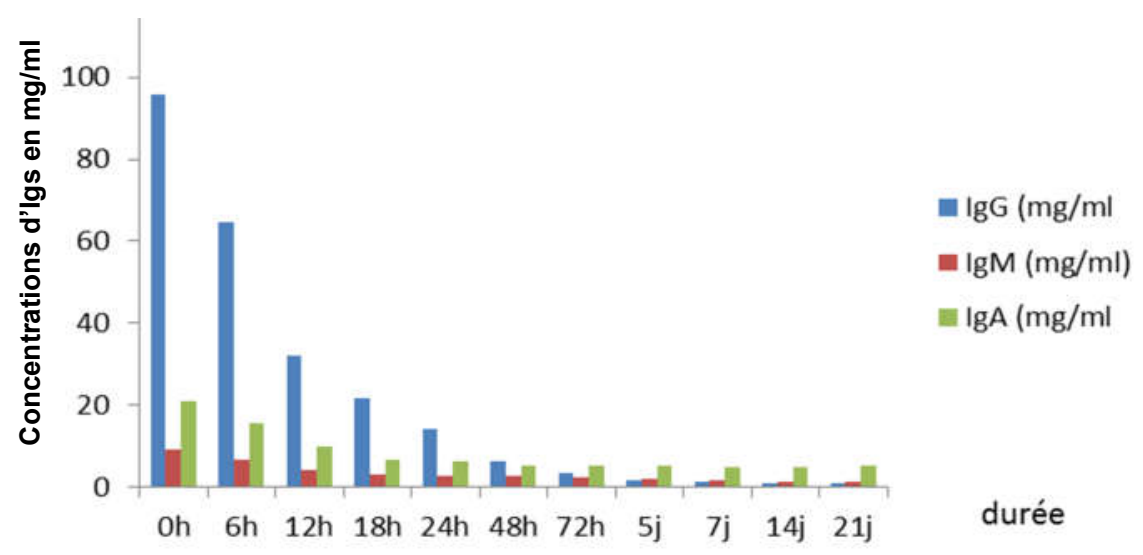

Figure 1 : Evolution dans le temps des concentrations en immunoglobulines du colostrum et du lait de truie après mise-bas (à partir du tableau de Klobasa et al., 1987). 


\section{MECANISME DE SYNTHESE DES COMPOSANTS IMMUNITAIRES DU COLOSTRUM.}

Les IgGs, IgMs et IgAs du colostrum proviennent du sang dans des proportions respectives de $100 \%, 85 \%$ et $40 \%$, tandis que chez la vache, le sang fournit au colostrum $100 \%$ des IgG1s, $60 \%$ des IgMs et $50 \%$ des IgAs, le reste de ces anticorps étant synthétisé par la glande mammaire (Salmon, 2011). Les IgAs du colostrum proviennent ainsi plus de la mamelle que du sang maternel contrairement aux IgGs et IgMs. Elles sont synthétisées par les cellules immunitaires qui migrent de l'intestin et des voies respiratoires supérieures à la glande mammaire (Foisnet et al., 2011). Ces proportions peuvent être expliquées par le fait que les cellules productrices d'IgA sont très peu nombreuses dans le sang et représentent 2 à $3 \%$ des lymphocytes totaux tandis que les cellules à IgG et $\operatorname{IgM}$ y représentent 10 à $12 \%$ (Chabaudie et al., 1987). Ces immunoglobulines sont transportées du sang dans la glande mammaire par les mêmes voies. De plus, les lymphocytes B synthétisent préférentiellement des IgAs que d'autres Igs au niveau de la glande mammaire.

\section{Transfert des Igs du sang dans la glande mammaire}

Chez la truie, les IgGs ont une demivie de 12 à 14 jours tandis que les IgAs et les IgMs ont respectivement les demi-vies de 36 heures et 3 jours (Baintner, 2007 ; Cervenak et Kacskovics, 2009). Ces immunoglobulines sont transférées du sang dans la glande mammaire par les voies trans-cellulaire et para-cellulaire. La quasi-totalité des IgGs et $85 \%$ des IgMs colostrales proviendraient donc des voies trans et para-cellulaires. La chute significative des concentrations colostrales d'IgG et d'IgM dans les 24 heures postpartum (Quesnel, 2011b) qui coïncide avec la fermeture des jonctions serrées des cellules épithéliales mammaires fait suggérer que la voie para-cellulaire est celle qui fournit la majorité de ces deux isotypes d'immunoglobulines au colostrum. Si la voie para-cellulaire fait intervenir les jonctions serrées, la voie trans-cellulaire est un processus spécifique de transcytose à travers la cellule épithéliale mammaire faisant appel aux récepteurs membranaires spécifiques qui fixent les Igs (Salmon, 2011). Les IgAs et les IgMs sont fixées alors par le récepteur polymérique pIgR pour lequel elles ont une affinité plus élevée (Salmon et al., 2009) et les IgGs se lient préférentiellement au récepteur néonatal $\mathrm{FcRn}$ des cellules épithéliales (Schnulle et Hurley, 2003 ; Hurley et Theil, 2011). Ces récepteurs sont spécifiques de la partie Fc de la molécule d'immunoglobuline (Hurley et Theil, 2011) et leur expression à travers celles des FcRn mRNA s'effectue dans la glande mammaire autour de la mise-bas (Schnulle et Hurley, 2003). Quant aux pIgR mRNA, leur accumulation dans la glande mammaire de la brebis débute au cours du dernier trimestre de la gestation et augmente durant la lactation sous l'influence combinée des hormones circulantes (prolactine et glucocorticoïdes) et de cytokines produites localement (Rinchev-Alarnold et al., 2002).

Le transfert des IgGs et IgAs du sang de la truie dans la mamelle se fait de manière non sélective (Bandrick et al., 2014). De façon apparemment simple, chaque immunoglobuline se lie au récepteur qui lui est spécifique à la surface basolatérale de la cellule épithéliale mammaire. Après son internalisation par un mécanisme d'endocytose, le complexe immunoglobulinerécepteur est transporté vers l'extrémité apicale de la cellule avant d'être libéré dans la lumière des alvéoles (Hurley et theil, 2011). Dans ce cas, la liaison du récepteur FcRn à l'IgG est dépendante du $\mathrm{pH}$, se produit à un $\mathrm{pH}$ acide et se défait avec la libération de l'IgG à un $\mathrm{pH}$ neutre ou basique (Stirling et al., 2005 ; Hurley et Theil, 2011). Quant aux IgA et IgM, elles se lient chacune au récepteur 
pIgR dont la dégradation partielle à la fin du transport, donne naissance à la pièce sécrétoire ( $\mathrm{SC}$ ) et aux molécules d'IgA et d'IgM, cette composante sécrétoire étant la partie extracellulaire du récepteur qui protégerait ces anticorps de la lyse protéolytique (Salmon, 2011).

\section{Synthèse locale des Immunoglobulines dans la glande mammaire}

La migration des lymphocytes vers la muqueuse de la glande mammaire de la truie conduit à la synthèse d'environ $60 \%$ des IgAs et $15 \%$ des IgMs par les cellules B génératrices d'anticorps, mais pas à celle des IgGs. Cette synthèse est la réponse immunitaire à une stimulation localisée au niveau de cette muqueuse.

Cette migration est un processus dénommé «Homing» ou «Domiciliation» coordonné depuis les sites d'induction jusqu'aux sites effecteurs par une association de protéines formée de cytokines chimiotactiques appelées chimiokines, de récepteurs et des protéines d'adhésion spécifiques au tissu comme les adressines (Kunkel et Butcher, 2003). L'induction ou l'activation des lymphocytes $\mathrm{B}$ favorise l'augmentation des récepteurs des chimiokines capables de transporter particulièrement les cellules à IgA à la surface des muqueuses et les cellules à $\operatorname{IgG}$ aux sites d'inflammation des tissus puis de manière générale, les cellules à Igs dans la moelle osseuse reconnue comme site important de synthèse des anticorps (Kunkel et Butcher, 2003). Les sites effecteurs ou d'implantation dépendent alors des sites d'activation et de cette association de protéines qui joue les rôles de transport et d'identifiant du tissu muqueux auquel chaque sous-population lymphocytaire doit être adressée au cours de sa migration. Les sites d'induction des tissus lymphoïdes associés à la muqueuse intestinale dénommés "Gut- Associated Lymphoid
Tissue" (GALT) sont le ganglion mésentérique et les plaques de Peyer.

D'une manière générale, la synthèse des Igs dans la glande mammaire dans le cadre d'une stimulation de l'intestin peut se faire de la manière suivante. Face à des antigènes présents dans l'environnement de la truie et de ses petits, l'intestin génère des plasmocytes à $\operatorname{IgM}, \operatorname{IgA}$ et $\operatorname{IgG}$ spécifiques à ces antigènes et seuls les plasmocytes portés par des récepteurs spécifiques à la glande mammaire (CCR10, $\alpha 4 \beta 1, \alpha 4 \beta 7)$ atteignent au cours de leur migration l'épithélium mammaire (Levast, 2010). C'est le cas des cellules à $\operatorname{IgA}$ et $\operatorname{IgM}$. De manière spécifique, dans les conditions naturelles, la stimulation dans le GALT des plasmocytes à IgA par des antigènes induit leur migration vers la glande mammaire où ils sécrètent des $\operatorname{IgA} d u$ colostrum et du lait (Roux et al., 1977). Chez la truie, ces plasmocytes à IgA activés atteignent la glande mammaire grâce aux adressines et chimiokines et c'est l'absence de ces adressines dans la glande mammaire des ruminants qui explique l'absence des plasmocytes à IgA (Levast, 2010 ; Salmon, 2011). Par contre, la non synthèse des IgGs par la glande mammaire pourrait également être expliquée par le fait que les plasmocytes à IgG activés n'atteignent aucun tissu muqueux (Bourges et al., 2007). Les sites inducteurs impliqués dans la synthèse des IgAs sont les muqueuses intestinale et pulmonaire (Salmon et al., 2010) et le tissu lymphoïde le plus impliqué est le GALT. Il existe un lien immun à la fois entre le tractus digestif, le tractus respiratoire supérieur et la glande mammaire qui aboutit au recrutement des plasmocytes à IgA (Bourges et al., 2007). Le lien immun entre le tractus digestif et la glande mammaire est le lien entéro-mammaire qui se manifeste par la réponse de l'intestin à un antigène aboutissant à la production en priorité d'Igs dans l'intestin et la dissémination par la suite des plasmocytes à Igs dans la glande mammaire. Ce lien explique le fait que le 
colostrum et le lait maternels ne contiennent que des anticorps spécifiques pour les agents pathogènes auxquels la truie a été exposée et qui peuvent être rencontrés par l'intestin du nouveau-né et d'autres tissus muqueux (Hurley et Theil, 2011). Ce lien pourrait être exploité dans la gestion efficace de l'immunité passive, car il pourrait expliquer la possibilité de protéger les porcelets à travers la vaccination des truies gestantes.

Par ailleurs, dans le souci de cette gestion efficace de l'immunité passive, il est important de connaître à quel moment la glande mammaire de la truie est colonisée par les plasmocytes. En effet, il semble que la période de colonisation de la glande mammaire par les lymphocytes varie suivant le type de lymphocyte. Les lymphocytes $\mathrm{T}$ colonisent la glande mammaire vers le $80^{\text {ème }}$ jour de gestation pendant un temps relativement court tandis que les lymphocytes B s'accumulent dans la glande mammaire à partir du $1^{\text {er }}$ jour pour les cellules à IgM et de 80 è au $1^{\text {er }}$ jour de lactation pour les lymphocytes $\mathrm{B}$ à IgA qui finissent leur maturation dans la glande mammaire (Chabaudie et al., 1987). Chez la truie, les sites préférentiels d'accumulation de ces lymphocytes à partir du $105^{\text {ème }}$ jour de gestation et surtout à la mise bas se retrouvent le long de l'épithélium alvéolaire, ce qui se justifie par le fait que $83,2 \%$ des lymphocytes à IgA sont sous épithéliaux au premier jour de lactation (Chabaudie et al., 1987). Une augmentation du nombre total de lymphocytes est alors observée dans le tissu mammaire de 80 à 105 jours de gestation (Salmon, 1987 ; Chabaudie et al., 1993). De même, chez la souris, le recrutement et la domiciliation des plasmocytes à IgA dans la glande mammaire s'effectuent à partir de la fin de gestation et pendant la période de lactation (Chabaudie et al., 1993). La prolactine pourrait jouer un rôle dans ce recrutement, puisqu'il existe une corrélation entre la densité des récepteurs de cette hormone dans le tissu mammaire de la truie et l'accumulation des lymphocytes dans cet organe (Salmon, 1987). Avec la présence de toutes les sous-populations lymphocytaires pendant la gestation et la lactation (Salmon, 1987 ; Chabaudie et al., 1993), la glande mammaire dispose d'un système immunitaire local capable d'assurer sa propre protection et celle du nouveau-né à travers la synthèse d'IgA (Chabaudie et al., 1987).

\section{Transfert de l'immunité colostrale au porcelet nouveau-né}

\section{Transfert des immunoglobulines}

Chez les artiodactyles, porcins et ruminants, le nouveau-né ne reçoit pas de protection immunitaire avant sa naissance en raison de l'imperméabilité placentaire aux immunoglobulines (Salmon et al., 2009). De plus, avec 6 couches histologiques séparant la circulation maternelle de celle du fotus, les espèces bovine, équine et porcine présentent la barrière placentaire la plus efficace (Salmon, 1984). Sur cette base, aucune Ig ne devrait être détectée chez le porcelet nouveauné à sa naissance avant l'ingestion du colostrum. Mais de faibles quantités d'IgG maternelles peuvent être transmises au fœetus à travers le placenta (Butler et al., 2002), puisque des concentrations très négligeables d'IgG ont été retrouvées dans le sang chez certains porcelets avant leur première ingestion de colostrum (Le Dividich et al., 2005). En controverse, aucunes IgG et IgA n'ont pu être détectées dans le sang des porcelets avant l'ingestion du colostrum par ceux-ci, indiquant qu'aucune Ig n'a pu passer du placenta vers le foetus chez les nouveau-nés immédiatement après la naissance (Cabrera et al., 2013 ; Bandrick et al., 2014). La question est en effet de savoir si les Igs sont transmises au fœtus via le placenta ou si elles sont synthétisées par le fœus lui-même. En réponse à cette question, il apparaît que les fotus peuvent produire in utero des IgGs et des IgMs suite à une stimulation d'antigène in utero et, spontanément, des cellules B 
productrices d'immunoglobulines ont été isolées des fœetus du porcelet (Rooke et Bland, 2002). De plus, les composants du système immunitaire du foetus du porcelet sont en place immédiatement avant la mise-bas et ce fotus peut synthétiser des $\operatorname{IgG}$ suite à la réponse à l'attaque d'un antigène in utero (Sinkora et al., 2002).

De tout ce qui précède, il ressort que le porcelet acquiert ses Igs à travers l'ingestion du colostrum et celles-ci peuvent être complétées par les Igs produites éventuellement par le foetus in utero. Mais d'autres études sont nécessaires pour clarifier cette question. Ce transfert d'Igs aux porcelets nouveau-nés à travers le colostrum fait intervenir deux phénomènes importants : la liaison des Igs à leur récepteur et le mécanisme d'absorption intestinale des macromolécules du colostrum.

\section{Les récepteurs et leur liaison avec les Igs dans l'intestin du porcelet}

Les immunoglobulines $G$ sont l'indicateur de l'immunité colostrale chez le porcelet. Cette immunité est tributaire du transport d'IgG de la mère au nouveau-né (Cervenak et Kacskovics, 2009). Ce transport de l'IgG à travers l'intestin néonatal vers le sang du porcelet s'effectue grâce au récepteur néonatal d'IgG ( FcRn) qui est le premier identifié chez les rongeurs (Simister et Rees, 1985). Deux types de récepteurs néonataux existent chez les mammifères, le récepteur acide-dépendant et le récepteur acideindépendant. Si les deux types se lient avec l'IgG dans un environnement légèrement acide ( $\mathrm{pH}$ entre 5 et 7), le récepteur acide-dépendant a la particularité d'être non fonctionnel à un $\mathrm{pH}$ légèrement alcalin des fluides tissulaires (Baintner, 2007). Chez le porc, le récepteur est exprimé aussi bien chez l'animal adulte que nouveau-né et son expression dans l'épithélium intestinal est maintenue pendant toute la durée de vie chez le porc, les humains et les primates non humains (Stirling et al., 2005). Son expression se fait dans l'intestin (jéjunum, cellules épithéliales des villosités qui tapissent l'intestin), le foie, les tissus du rein et de la rate, l'endothélium capillaire et les monocytes (Stirling et al., 2005). Ces différents lieux d'expression de ce récepteur font suggérer ses rôles suivants : l'homéostasie des IgG (Stirling et al., 2005), le transfert de l'immunité passive chez le porc (Stirling et al., 2005, Cervenak et Kacskovics, 2009) et la présentation de l'antigène au système immunitaire porcin. Par ailleurs, en dehors de sa fonction de transport, le récepteur FcRn protège les IgGs de la dégradation rapide tout au long de leur vie et particulièrement contre celle des lysosomes (Cervenak et Kacskovics, 2009; Cabrera et al., 2013).

Avant de transporter les IgGs à travers la barrière de l'épithélium intestinal, le FcRn doit les reconnaitre et établir une liaison avec elles, cette liaison étant plus forte au $\mathrm{pH}$ compris entre 6-6,5 et significativement réduite au $\mathrm{pH}$ physiologique de 7,4 (Stirling et al., 2005). Il y a peu de liaison du récepteur à l'IgG porcine au pH 7,8 alors que cette liaison est clairement observée au pH 6,0 (Stirling et al., 2005). Cet environnement favorable à cette liaison est trouvé dans l'intestin grêle proximal des mammifères allaités et dans les vésicules, vacuoles et endosomes de différents types de cellules (Baintner, 2007). Cette liaison est intra-espèces, mais peut être aussi inter-espèces, car les récepteurs FcRn d'un mammifère donné peuvent se lier aux IgGs de divers mammifères et aux sous-classes $d$ 'IgG avec de très différentes affinités, ce qui n'est pas le cas avec les récepteurs IgY des poulets (Baintner, 2007). De plus, la capacité du récepteur porcin à se lier et internaliser l'IgG humaine et les expériences utilisant la lignée cellulaire de rein de porc (RS2) ont permis de conclure que le FcRn porcin était capable de prendre l'IgG de plusieurs espèces, y compris celle des bovins (Stirling et al., 2005). La conséquence de ces observations se traduit par le fait que le colostrum hétérologue peut être 
utilisé comme source d'IgG chez les porcelets nouveau-nés. D'ailleurs, des IgGs bovines ont été retrouvées dans le sang des porcelets nourris au colostrum de la vache (Drew et Owen, 1988 ; Stirling et al., 2005). A ce niveau, la capacité des IgGs bovins à réagir aux pathologies porcines demeure une question de recherche. Toutefois il a été observé que les immunoglobulines porcines ont été absorbées beaucoup plus facilement que les Igs bovines par les porcelets (Drew et Owen, 1988).

\section{Absorption intestinale des Igs et transfert de l'immunité passive au porcelet nouveau-né}

L'absorption intestinale des immunoglobulines colostrales est un processus non spécifique et non sélectif (Salmon et al., 2010 ; Hurley et Theil, 2011 ; Bandrick et al., 2014). Un bon transfert d'Igs est le résultat d'une ingestion immédiatement à la naissance d'une quantité suffisante de colostrum riche en Igs, de l'arrivée de ces Igs sous forme intactes au site d'absorption et de leur passage du tractus gastro-intestinal au sang.

Après leur absorption, les $\operatorname{IgG}, \operatorname{IgM}$ et IgA se retrouvent dans le sang du porcelet dans les rapports d'isotypes identiques à ceux du colostrum (Salmon et al., 2010), d'où l'importance de l'ingestion d'un colostrum riche en Igs. D'ailleurs, un niveau plus élevé d'IgGs dans le colostrum est favorable à leur forte concentration dans le sang et une protection systémique plus longue (Salmon et al., 2010), mais à condition que ce colostrum soit ingéré en quantité suffisante par le porcelet immédiatement à la naissance. En effet, la plus grande absorption d'IgG a été observée lorsque les porcelets ont reçu du colostrum immédiatement après leur naissance et la période recommandée pour le gavage des porcelets en cas de leur supplémentation avec du colostrum porcin/bovin, est aussitôt à la naissance (Cabrera et al., 2013). De plus, l'ingestion du colostrum par le porcelet est positivement corrélée avec la concentration sérique d'IgG (Ferrari et al., 2014).

L'absorption intacte des Igs, c'est-àdire non désagrégées dans l'intestin grêle des porcelets est permise par l'état enzymatique du tube digestif et la propriété enzymatique du colostrum. Le passage intact des IgGs dans l'intestin grêle se fait alors à la faveur : de la protection de l'Ig contre les protéases par le récepteur FcRn, de la faible activité protéolytique intestinale (faible sécrétion d'HCl et de pepsinogène) et de la forte teneur $\mathrm{du}$ colostrum en inhibiteurs de trypsine et de chymotrypsine, bien entendu, les immunoglobulines du colostrum des mammifères dont les porcins sont particulièrement sensibles à la trypsine (Baintner, 2007). De plus, cette absorption est possible grâce à la capacité des entérocytes fœtaux à internaliser les immunoglobulines par endocytose. Cette endocytose se fait après la liaison des Igs avec leurs récepteurs respectifs dans la partie apicale des cellules épithéliales ( $\mathrm{pH}$ favorable) après quoi le complexe Ig-récepteur est transporté dans des vésicules formées par invagination de la membrane des cellules ou vésicules de pinocytose vers la membrane baso-latérale des entérocytes où les Igs sont libérées dans le sang via la lymphe à un $\mathrm{pH}$ légèrement alcalin (Stirling et al., 2005). Le transport des immunoglobulines à travers la membrane baso-latérale de l'entérocyte est alors déterminant dans leur passage vers la circulation sanguine (Rooke et Bland, 2002). Les immunoglobulines absorbées par l'épithélium se retrouvent à $2 \mathrm{~h}$ après la naissance dans le duodénum, $24 \mathrm{~h}$ dans le jéjunum et $48 \mathrm{~h}$ dans l'iléon (Murata et al., 1977). Après absorption, les quantités sériques $\mathrm{d}^{\prime} \operatorname{IgG}$ et $\mathrm{d}^{\prime} \operatorname{Ig} \mathrm{A}$ du porcelet sont estimées à environ $20 \mathrm{mg} / \mathrm{ml}$ et $1,6 \mathrm{mg} / \mathrm{ml}$ respectivement (Bandrick et al., 2014). Une concentration sérique maximale d'IgG de 26 à $27 \mathrm{mg} / \mathrm{ml}$ a été observée chez les porcelets ayant une ingestion maximale de colostrum 
(Le Dividich et al., 2005). Une fois dans le sang des porcelets, les immunoglobulines maternelles colostrales subissent un catabolisme qui a lieu dans les lysosomes et régulé par la médiation des FcRn (Cervenak et Kacskovics, 2009) avec l'élimination de la moitié des IgGs en 15 jours, des IgMs en 4 jours et des IgAs en 3 jours (Salmon et al., 2010). Elles sont alors remplacées par les immunoglobulines propres du porcelet. Il s'agit alors d'une transition vers l'immunité active se traduisant par la synthèse par le porcelet de ses propres anticorps qui commence à 7 jours de vie pour les IgGs et à 10 jours pour les IgAs et IgMs (Salmon et al., 2010). Cette immunité active est positivement corrélée avec le niveau d'acquisition de l'immunité passive (Le Dividich, 2006).

Enfin, en dehors de la muqueuse intestinale, les anticorps colostraux peuvent également pénétrer la barrière broncho-alvéolaire des poumons des nouveau-nés (Charley et Corthier, 1977 ; Nechvatalova et al., 2011). Par contre, cette pénétration semble impossible chez les animaux adultes, car aucune immunoglobuline n'a pu pénétrer la barrière bronchoalvéolaire des poumons normaux chez les porcs en croissance et adultes (Charley et Corthier, 1977). La pénétration des voies respiratoires par les immunoglobulines a lieu apparemment via le récepteur FcRn pour les IgGs (Nechvatalova et al., 2011) et le récepteur pIgR pour les IgAs (Salmon, 2011).

\section{Facteurs influençant l'absorption intestinale et le transfert des Igs dans le sang}

L'absorption des Igs chez le porcelet peut être influencée par des facteurs exogènes et endogènes (liés à l'animal).

Le principal facteur endogène est relatif aux changements de perméabilité de l'intestin. En effet, le processus d'absorption et de passage des macromolécules dans le sang des porcelets n'est permis que pendant un temps relativement court après lequel on observe le phénomène dénommé « Gut closure » ou fermeture de l'intestin. Ce temps est de 24 à 36 heures après la naissance (Rooke et Bland, 2002 ; Baintner, 2007 ; Quesnel, 2011a). Il peut être plus court (Cabrera et al., 2013) et se situer dans un intervalle de 12 à 18 heures après la naissance au-delà duquel s'arrête le processus de transfert des immunoglobulines dans le sang des porcelets (Le Dividich, 2006). Il faut faire remarquer que la fermeture de l'intestin correspond à la cessation du transfert des Igs à travers la membrane baso-latérale de l'entérocyte, donc de leur transfert dans la circulation sanguine du porcelet (Rooke et Bland, 2002). Ce qui veut dire que l'entérocyte peut continuer à internaliser les Igs après le « gut closure ». Il peut y avoir une saturation, car chaque entérocyte n'est capable d'absorber qu'une quantité limitée de matière par pinocytose (Rooke et Bland, 2002). Il semble que la fermeture de l'intestin n'est pas totale même après 36 heures puisque de petites quantités de macromolécules sont transmises dans le sang de porcs en croissance tout au long de la période d'allaitement et au moins quelques semaines après le sevrage (Svendsen et al., 1990). De même, l'absorption des IgGs colostrales bovine et porcine est possible chez l'animal adulte (animaux plus âgés de 4 semaines) (Stirling et al., 2005). Ces observations pourraient orienter le débat sur les causes de l'arrêt de l'absorption des Igs qui ne sont pas encore complètement élucidées à notre connaissance.

S'agissant des facteurs exogènes, l'énergie et la prise du colostrum sont entre autres des facteurs qui pourraient affecter l'absorption des Igs.

Selon sa source, l'énergie peut influencer positivement ou négativement l'absorption des IgGs chez le porcelet. Contrairement au lactose qui a un effet dépressif sur l'absorption des IgGs durant les premières 24 heures de vie du porcelet (Rooke et Bland, 2002), le dextrose et les huiles végétales 
favorisent une grande absorption de ces immunoglobulines (Bikker et al., 2010).

Bien que le colostrum, grâce à ses peptides bioactives, ses facteurs de croissance et ses hormones, stimule le développement fonctionnel et structural du tractus gastrointestinal du porcelet (Wolinski et al., 2003), son ingestion favorise la fermeture de l'intestin (Rooke et Bland, 2002). Cette ingestion, lorsqu'elle est faible et continue, peut induire l'arrêt de la perméabilité intestinale (Le Dividich, 2006).

De tout ce qui précède, une consommation adéquate (quantité et concentration en Igs) immédiatement à la naissance et dans un temps relativement court est gage d'un bon transfert d'immunité passive ou colostrale au porcelet. Tout le processus de ce transfert est décrit par la Figure 2.

\section{Transfert des cellules et des facteurs antimicrobiens aux porcelets}

Comme dans le cas des Igs, le transfert de l'immunité cellulaire aux porcelets se fait à travers l'absorption du colostrum. Ceci a été démontré par le fait que les lymphocytes des porcelets ayant ingéré du colostrum des truies vaccinées contre Mycoplasma hyopneumoniae étaient capables de proliférer et de répondre à la stimulation d'antigène spécifique du mycoplasme (Bandrick et al., 2008). Le lieu d'absorption de ces cellules maternelles est l'épithélium intestinal néonatal et préférentiellement la muqueuse duodénale (Le jan et Chevaleyre, 1996) et cette absorption se fait de façon sélective (Bandrick et al., 2014). Les cellules colostrales ne peuvent traverser la muqueuse intestinale du porcelet que si elles sont non seulement vivantes mais doivent provenir de la propre mère du porcelet (Salmon et al., 2010). La conséquence pratique de ces caractéristiques des cellules immunitaires se traduit par le fait qu'en cas d'alimentation des porcelets avec uniquement $\mathrm{du}$ colostrum provenant d'une truie autre que leur mère ou de leur adoption, ceux-ci seront déficitaires en cellules immunitaires. Il en sera de même dans le cas d'une alimentation avec du colostrum hétérologue. Une fois absorbées, ces cellules colostrales traversent l'épithélium du duodénum et du jéjunum pour se retrouver dans le ganglion mésentérique par la lymphe et se disséminer finalement dans l'organisme par voie sanguine (Salmon, 2011). Une fois dans le sang du porcelet, les cellules colostrales maternelles ont la capacité de favoriser le développement et la maturation des cellules présentatrices d'antigène néonatales, le développement rapide des lymphocytes néonataux et leur activation (Reber et al., 2008) et donc d'influencer la réponse immunitaire innée et adaptative des porcs nouveau-nés (Bandrick et al., 2014). Il est utile de signaler que le mécanisme de transport des lymphocytes maternels à travers l'épithélium intestinal du nouveau-né reste encore non élucidé (Bandrick et al., 2014).

$\mathrm{Si}$ le mécanisme de transfert des cellules immunitaires mérite d'être approfondi, celui de la lactoferrine, l'un des plus importants facteurs antimicrobiens, se fait par endocytose via les cellules épithéliales (Harada et al., 1999). La lactoferrine est alors transportée de la lumière intestinale par le sang et excrétée dans la bile, suggérant la possibilité d'une circulation entéro-hépatique de la lactoferrine chez les porcs nouveau-nés. En dehors de sa synthèse par les porcelets, l'haptoglobine est aussi transférée de la mère au nouveau-né par le colostrum (Hiss-Pesch et al., 2011).

Tout comme les cellules et les anticorps, les cytokines sont transmises aux porcelets par le colostrum. En effet, les cytokines du sérum des porcelets conventionnels proviennent principalement du colostrum de la truie (Nguyen et al., 2007). Une absorption maximale des cytokines du colostrum dans le sang des porcelets est observée à 1-2 jours post-partum 
correspondant à la période de fermeture de l'intestin (Nguyen et al., 2007).

Facteurs influençant la quantité de colostrum et sa qualité immunitaire chez la truie

\section{Facteurs de variation du rendement de colostrum}

La quantité de colostrum produite varie beaucoup entre les truies (Quesnel, 2011b) et peut être influencée par des facteurs liés à l'animal et des facteurs exogènes. Les facteurs endogènes comme la taille de portée, le poids de la portée à la naissance et la durée de parturition n'influencent pas le rendement du colostrum (Foisnet et al., 2010a et 2011 ; Quesnel, 2011a et 2011b; Declerck et al., 2015).

S'agissant des autres facteurs endogènes, la parité est reconnue avoir impacté la production colostrale chez la truie, les truies de parité 2 et 3 semblant avoir un rendement plus élevé que les primipares et les truies plus âgées (Quesnel et al., 2015). La corrélation positive observée entre le rendement de colostrum et les concentrations plasmatiques d'urée et de créatinine de la truie durant la période prépartum témoigne du rôle important du statut métabolique de la truie dans la production colostrale (Loisel et al., 2014). Quant au statut hormonal, son influence est lié au ratio $\mathrm{PRL} / \mathrm{P} 4$, puisque ce rapport à 24 heures prépartum élevé, synonyme d'une concentration péripartum sanguine faible de P4 et forte de PRL conduit à une augmentation du rendement de colostrum chez les truies primipares (Loisel et al., 2015). S'agissant de la durée de gestation, elle est négativement corrélée avec le rendement du colostrum (Declerck et al., 2015). Enfin le développement de la glande mammaire constitue un facteur potentiel de variation de la production du colostrum (Quesnel et al., 2015), mais des études méritent d'être menées sur ce sujet.
Concernant l'effet des facteurs exogènes sur le rendement colostral, l'alimentation des truies en fin de gestation pourrait influencer le rendement du colostrum de la truie (Quesnel et al., 2015), mais ces questions méritent toujours d'être approfondies. Quant à l'induction de la mise-bas, elle n'influence pas le rendement du colostrum (Foisnet et al., 2010a et 2011).

\section{Qualité immunitaire du colostrum de truie et facteurs de variation}

Tout comme le rendement du colostrum de la truie, sa composition immunitaire peut être influencée par des facteurs exogènes et endogènes. Le Tableau 2 résume les effets de quelques facteurs.

S'agissant des facteurs endogènes, la taille de portée et la durée de gestation n'influencent pas la concentration d'IgG du colostrum (Quesnel, 2011b). Par contre, l'effet de la parité sur la concentration colostrale d'Igs est remarquable chez la truie avec une plus forte concentration d'IgG et d'IgA dans le colostrum des multipares (à partir de parité 4) (Quesnel, 2011b ; CarneyHinkle et al., 2013). L'effet de la position des tétines sur la qualité du colostrum a été aussi observé, le colostrum des mamelles antérieures étant plus riche en Igs que celui des postérieures (Wu et al., 2010).

Parmi les facteurs exogènes soupçonnés avoir d'effet sur la qualité immunitaire $\mathrm{du}$ colostrum chez la truie, l'immunostimulation non spécifique de la truie augmente la concentration d'IgG du colostrum (Krakowski et al., 2002), tandis que l'induction de la mise-bas a un effet passif sur la concentration d'IgG et diminue la concentration d'IgA (Foisnet et al., 2010b, 2011 ; Quesnel, 2011b). Cette différence de l'effet de l'induction sur les IgG et IgA serait liée à la différence entre les voies de transfert de ces anticorps dans le colostrum (Foisnet et al., 2011). 
Les études sur l'alimentation de la truie font appel à la supplémentation pendant la gestation avec surtout des matières premières non conventionnelles et de certains nutriments. En dehors de la nature de la ration, la période de gestation pour la supplémentation et sa durée semblent déterminants dans l'efficacité du supplément.

Une supplémentation des truies à 103 jours de gestation avec des huiles de coprah, de poisson et de foie de requin, n'a eu aucun effet sur les concentrations d'IgG et d'IgA du colostrum (Boudry et al., 2012). Par contre, avec une durée plus longue de supplémentation (dernier tiers de gestation et la lactation), l'huile de foie de requin a augmenté le taux d'IgG (Boudry et al., 2012). De même, les huiles de palme et de tournesol augmentent plus les concentrations colostrales d'Igs lorsqu'elles sont administrées à la première moitié de gestation (60 premiers jours) que si la supplémentation a lieu durant la dernière moitié (de 61 jours à la mise-bas) (Laws et al., 2009). L'effet de ces huiles serait dû à une grande ingestion de $\beta$-carotène et de vitamine $\mathrm{E}$ par la truie à travers l'huile de palme et l'huile de tournesol respectivement (Laws et al., 2009). Enfin, Saccharomyces cerevisiae en supplément à la truie durant toute la période de gestation et la lactation n'a eu aucun effet sur la concentration d'IgG (Shen et al., 2011). Ce résultat pourrait être dû à la source du produit et à la dose, puisque l'administration de trois souches différentes de Saccharomyces cerevisiae à 80 jours de gestation jusqu'à la lactation n'a augmenté significativement la concentration d'IgG qu'avec deux souches (Zanello et al., 2013). De plus, l'effet de la dose n'a pas été observé pour l'une de ces deux souches, mais est remarquable pour la seconde souche. Ensuite, l'apport de Saccharomyces cerevisiae boulardii, un probiotique distribué aux truies gestantes en fin de gestation (21j) améliore les concentrations d'IgG (Guillou et al., 2012).
Par ailleurs, les acides linoléiques conjugués, les acides gras d'origine marine, les extraits d'algue «Laminaria spp », les fructo-oligosaccharides, les taux élevés de fibre, les acides gras n-3 d'huile de poisson, le rapport acide gras Omega-3/Omega-6 et les extraits de gingembre ont fait l'objet d'études de supplémentation de la truie gestante.

Les acides linoléiques conjugués augmentent les concentrations colostrales d'IgG, d'IgA et d'IgM, mais diminuent celle d'IgE par un mécanisme non encore complètement élucidé (Corino et al., 2009). Mais il se pourrait que le mode d'action de ces acides, favorisant la synthèse des IL-2 et la diminution des IL-4 conduise à ce résultat car les IL-4 sont responsables de la synthèse des IgEs alors que les IL-2 contribuent à la production des autres immunoglobulines (Corino et al., 2009). Par ailleurs, la supplémentation des truies en fin de gestation en acide gras linoléique conjugué augmente significativement la concentration en IgG du sang des truies et de leur colostrum (Rossi et al., 2004).

Comme les acides gras d'origine marine (Foubert et al., 2009), les extraits d'algue «Laminaria spp » augmentent la concentration d'IgG du colostrum grâce à la propriété immuno-modulatrice de la laminarine qui est un polymère hydrosoluble de glucose ( $\beta$-glucane) contenu dans l'algue (Leonard et al., 2010). Par contre, le taux élevé de fibres dans la ration diminue la concentration d'IgA du colostrum, résultat qui pourrait être lié au changement dans la microflore de l'intestin de la truie induit par les fibres ou au changement dans l'expression des récepteurs pIgR dans la glande mammaire induit par les fibres à travers leur effet probable sur l'expression des cytokines et métabolites qui ont la capacité d'influencer la synthèse de ce récepteur (Loisel et al., 2013). La supplémentation des truies gestantes avec des acides gras n-3 d'huile de poisson augmente la concentration d' $\mathrm{IgG}$ du colostrum (Mateo et al., 2009) alors que la modification 
du rapport acide gras Omega-3/Omega-6 ou Omega-6/Omega-3 n'ont pas eu d'effet sur les concentrations colostrales d'IgG et d'IgA (Eastwood et al., 2014).

S'agissant des oligosaccharides, la teneur du colostrum en IgA et en TGF $\beta 1$ a été significativement améliorée grâce à la supplémentation des truies pendant les 4 dernières semaines de gestation avec des fructo-oligosaccharides à chaînes courtes (Apper-Bossard et al., 2013).

Enfin, l'extrait de gingembre dans la ration des truies gestantes augmente significativement le taux d'IgG du sang des truies et de leur colostrum grâce à son activité d'antioxydant (Lee et al., 2013).

En résumé, ces études ont prouvé la possibilité d'améliorer la qualité immunitaire du colostrum à travers l'alimentation de la truie durant la gestation. Mais pour assurer la survie du porcelet, il faut un mécanisme pouvant améliorer à la fois la quantité et la qualité du colostrum. L'association d'autres nutriments susceptibles d'augmenter le rendement du colostrum à ces rations ayant un effet positif sur la qualité immunitaire pourrait être l'une des voies à explorer. Dans ce cas, l'étude sur l'utilisation des plantes lactogènes chez les truies est une option envisageable, compte-tenu des résultats obtenus par certains chercheurs sur d'autres espèces. Ces plantes ont une capacité de stimuler la biosynthèse de la caséine- $\beta$ et la sécrétion de toutes les hormones impliquées dans la lactation, particulièrement la prolactine, les hormones de croissance, le cortisol (Sawadogo, 1987). Les extraits aqueux de tourteaux de coton ont également une capacité à induire la biosynthèse de caséine- $\beta$ dans la glande mammaire des rattes et des lapines et à stimuler la sécrétion de prolactine, d'hormone de croissance et de cortisol chez la brebis (Sawadogo, 1987). Par ailleurs, le pouvoir lactogène de deux plantes, Euphorbia hirta et Secamone afzelii a été démontré car les extraits aqueux de ces plantes augmentent le taux de prolactine dans le sang des rates (Adepo et al., 2010). De même, les extraits bruts et partiellement purifiés de certaines plantes (coma, lin, angozé et coton) injectées à des brebis par voie intraveineuse stimulent la sécrétion de la prolactine (Sepehri et al., 1992). Enfin, l'extrait aqueux de Acacia nilotica andosonii, plante lactogène souvent utilisée au Burkina Faso, stimule la production du lait et la synthèse de la prolactine chez la ratte (Lompo-Ouedraogo et al., 2004).

Tableau 2 : Facteurs influençant la concentration d'immunoglobulines du colostrum de truie.

\begin{tabular}{lll}
\hline Facteurs & Effets & Auteurs \\
\hline & \multicolumn{1}{c}{ Facteurs liés à la truie } & \\
\hline $\begin{array}{l}\text { Immunostimulation non } \\
\text { spécifique de la truie }\end{array}$ & $\begin{array}{l}\text { Augmentation de la concentration d'IgG du } \\
\text { colostrum }\end{array}$ & $\begin{array}{l}\text { Krakowski et al., } \\
2002\end{array}$ \\
\hline & $\begin{array}{l}\text { Augmentation des concentrations d'IgG et } \\
\text { IgA du colostrum : } \\
\text { colostrum des truies de parité 4 plus riche } \\
\text { en IgG et IgA que celui de parité 1 (Etude } \\
\text { sur truies de parités 4 et 1) }\end{array}$ & $\begin{array}{l}\text { Carney-Hinkle et al., } \\
\text { 2013 }\end{array}$ \\
\cline { 2 - 3 } & $\begin{array}{l}\text { Pas d'effet sur la concentration d'IgG du } \\
\text { colostrum }\end{array}$ & Quesnel, 2011b \\
& $\begin{array}{l}\text { Pas d'effet sur la concentration d'IgG du } \\
\text { colostrum }\end{array}$ & Quesnel, 2011b \\
\hline $\begin{array}{l}\text { Taille de portée et durée } \\
\text { gestation }\end{array}$ & &
\end{tabular}




\begin{tabular}{|c|c|c|}
\hline \multirow{2}{*}{ Induction de la mise-bas } & $\begin{array}{l}\text { Pas d'effet sur la concentration d'IgG du } \\
\text { colostrum }\end{array}$ & $\begin{array}{l}\text { Foisnet et al., 2010b, } \\
2011 \text {; } \\
\text { Quesnel, 2011b }\end{array}$ \\
\hline & $\begin{array}{l}\text { Diminution de la concentration d'IgA du } \\
\text { colostrum }\end{array}$ & Foisnet et al., 2011 \\
\hline Position des tétines & $\begin{array}{l}\text { Influence sur la concentration d'IgG du } \\
\text { colostrum : colostrum des mamelles } \\
\text { antérieures plus riche en IgG que celui des } \\
\text { mamelles postérieures }\end{array}$ & Wu et al., 2010 \\
\hline \multicolumn{3}{|c|}{ Supplémentation alimentaire des truies gestantes } \\
\hline Acides linoléiques conjugués & $\begin{array}{l}\text { Augmentation des concentrations du } \\
\text { colostrum en IgG, IgA et IgM } \\
\text { et diminution de la concentration d'IgE }\end{array}$ & Corino et al., 2009 \\
\hline Saccharomyces cerevisiae & $\begin{array}{l}\text { Pas d'effet sur la concentration du } \\
\text { colostrum en IgG }\end{array}$ & Shen et al., 2011 \\
\hline Acides gras d'origine marine & $\begin{array}{l}\text { Augmentation de la concentration du } \\
\text { colostrum en IgG }\end{array}$ & Foubert et al., 2009 \\
\hline Extraits d'algue Laminaria spp & $\begin{array}{l}\text { Augmentation de la concentration du } \\
\text { colostrum en IgG }\end{array}$ & Leonard et al., 2010 \\
\hline Extraits de gingembre & $\begin{array}{l}\text { Augmentation de la concentration du } \\
\text { colostrum en IgG }\end{array}$ & Lee et al., 2013 \\
\hline Taux élevé de fibres & $\begin{array}{l}\text { Diminution de la concentration du } \\
\text { colostrum en IgA }\end{array}$ & Loisel et al., 2013 \\
\hline $\begin{array}{l}\text { Acides gras } \mathrm{n}-3 \text { d'huile } \\
\text { poisson }\end{array}$ & $\begin{array}{l}\text { Augmentation de la concentration du } \\
\text { colostrum en IgG }\end{array}$ & Mateo et al., 2009 \\
\hline $\begin{array}{l}\text { Huiles de coprah, de poisson et } \\
\text { de foie de requin }\end{array}$ & Pas d'effet sur IgG et IgA & Boudry et al., 2012 \\
\hline Huiles de palme et de tournesol & $\begin{array}{l}\text { Augmentation des concentrations du } \\
\text { colostrum en IgG, IgA et IgM }\end{array}$ & Laws et al., 2009 \\
\hline
\end{tabular}




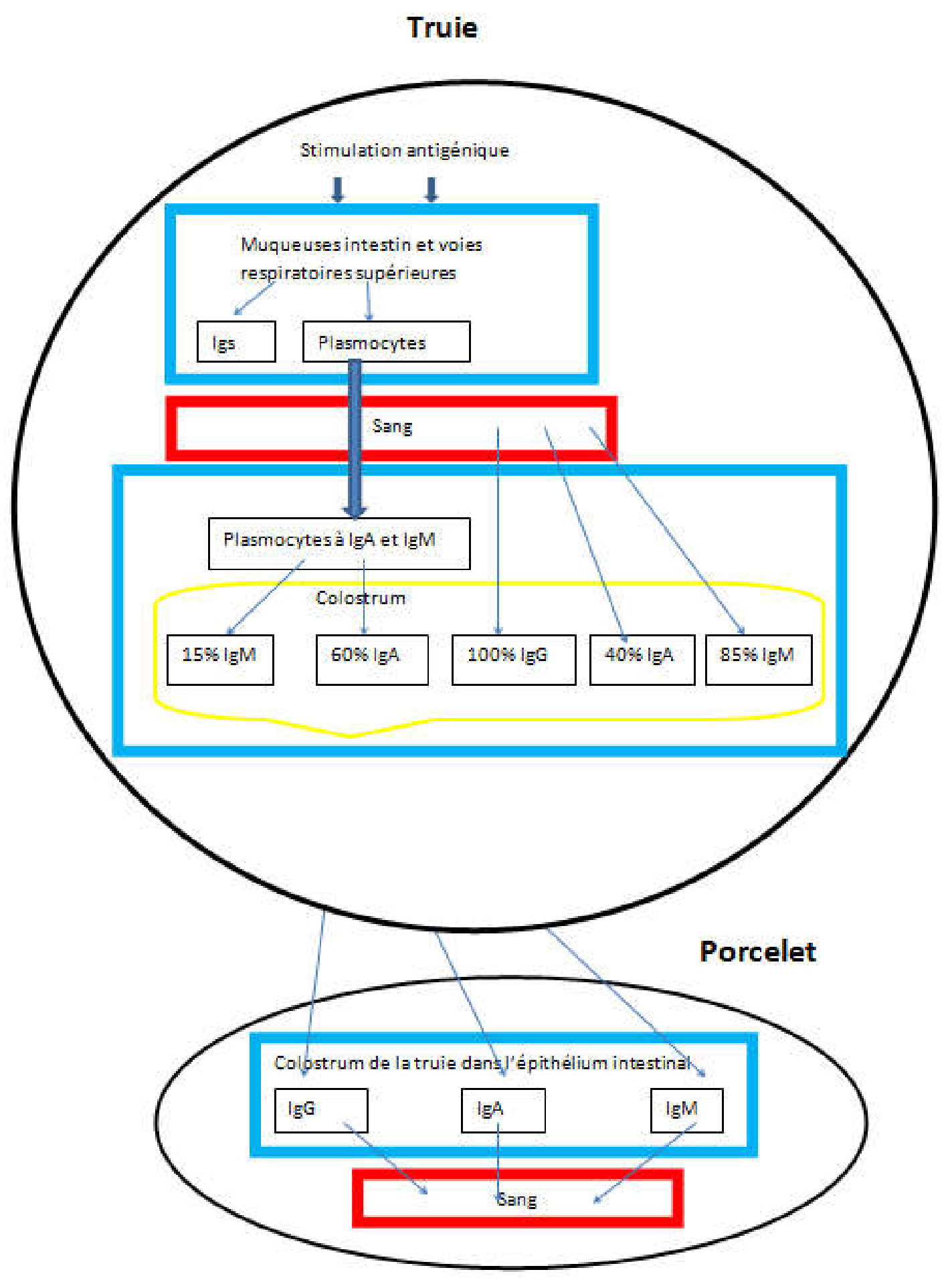

Figure 2 : Processus de transfert de l'immunité colostrale chez les porcins. 


\section{Conclusion}

La survie des porcelets à la naissance est assurée par les constituants de son colostrum formés de substances nutritives, de promoteurs de croissance et de facteurs immunitaires représentés par les immunoglobulines (Igs), les cellules immunitaires et les composés antimicrobiens. Le transfert de ces facteurs immunitaires aux porcelets via le colostrum de leur mère constitue l'immunité colostrale. Ce transfert est favorisé par une perméabilité non sélective de l'intestin pour les Igs, sélective pour les cellules immunitaires et d'une durée relativement courte. Le transfert des cellules immunitaires au porcelet exige que celles-ci soient vivantes et proviennent de la mère génétique du porcelet. Ceci rend alors déficitaire en cellules immunitaires les porcelets adoptés ou nourris avec du colostrum hétérologue. Pour que le transfert de l'immunité colostrale soit adéquat, il faut que la truie produise en quantité suffisante un colostrum riche en facteurs immunitaires et que le porcelet en ingère une quantité suffisante dans les minutes suivant la naissance et jusqu'à 24 heures de sa vie. Dans ce contexte, en plus des voies d'immunisation de la truie, la voie d'alimentation de la truie gestante doit être encouragée compte tenu des résultats obtenus par de récents travaux dans ce domaine. Dans ce cas, la voie de l'alimentation de la truie devra alors permettre la production en quantité et en qualité du colostrum. Si plusieurs études ont révélé l'effet positif de la supplémentation alimentaire de la truie gestante sur la qualité immunitaire de son colostrum, les pistes d'amélioration du rendement colostral sont encore presque vierges et méritent d'être explorées. L'une des pistes envisageables est l'effet des plantes lactogènes sur le rendement de colostrum chez la truie compte tenu des résultats obtenus sur d'autres espèces. A défaut de résultats concluants de ces études, l'apport d'Igs à travers la supplémentation des porcelets avec du colostrum hétérologue pourrait être une possibilité pour satisfaire ces contraintes de quantité et de qualité. Le colostrum bovin semble alors indiqué dans ce cas de figure.

\section{REFERENCES}

Adepo YP, Seka A, Biego HG, Chatigre KO, Kati CS. 2010. Étude de l'évolution des paramètres physico-chimiques de 2 plantes euphorbia hirta et secamone afzelii en fonction des quatre saisons de l'année, de l'extraction aqueuse et évaluation du pouvoir lactogène. Bull. Soc. Roy. Sci. liege., 79: 12-24. DOI: http://popups.ulg.ac.be/00379565/index.php?id=2323

Apper-Bossard E, Le Bourgot C, FerretBernard S, Blat S, Respondek F, LE Huërou-Luron I. 2013. Effets d'une supplémentation alimentaire peripartum en fructo-oligosaccharides à chaînes courtes sur le statut immunitaire et les performances de croissance des porcelets. Jour. Rech. Porc., 45: 275276.

Baintner K, 2007. Transmission of antibodies from mother to young: Evolutionary strategies in a proteolytic environment. Vet. Immunol. Immunopathol., 117: 153-161. DOI: 10.1016/j.vetimm.2007.03.001

Bandrick M, Pieters M, Pijoan C, Molitor TW. 2008. Passive Transfer of Maternal Mycoplasma hyopneumoniae-Specific Cellular Immunity to Piglets. Clin. Vaccine. Immunol., 15(3): 540-543. DOI:10.1128/CVI.00466-07

Bandrick M, Ariza-Nieto C, Baidoo SK, Molitor TW. 2014. Colostral antibodymediated and cell-mediated immunity contributes to innate and antigenspecific immunity in piglets. Dev. Comp. Immunol., 43(1): 114-120. DOI:10.1016/j.dci.2013.11.005

Bikker P, Kranendonk G, Gerritsen R, Russell L, Campbell J, Crenshaw J, 
Rodriguez C, Rodenas J, Polo J. 2010. Absorption of orally supplied immunoglobulins in neonatal piglets. Livest. Sci., 134(1-3): 139-142. DOI:10.1016/j.livsci.2010.06.119

Boudry C. 2009. Effets biologiques et immunitaires du colostrum bovin sur le porcelet au sevrage. Thèse de doctorat, Faculté Universitaire des Sciences Agronomiques de Gembloux, Gembloux, p. 141.

Boudry C, Vanrobays M-L, De Vos S. 2012. Influence de l'apport de différentes sources lipidiques en fin de gestation sur les résultats techniques des truies allaitantes et de leurs porcelets. Jour. Rech. Porc., 44 : 191-192.

Bourges D, Chevaleyre C, Wang C, Berri M, Zhang $\mathrm{X}$, Nicaise L, Meurens F, Salmon H. 2007. Differential expression of adhesion molecules and chemokines between nasal and small intestinal mucosae: implications for T- and $\operatorname{sg} \mathrm{A}+$ B-lymphocyte recruitment. Immunol., 122(4): 551-561. DOI: $0.1111 / \mathrm{j} .1365-$ 2567.2007.02671.x

Butler JE, Sun J, Weber P, Ford SP, Rehakova Z, Sinkora J. 2002. Switch recombination in fetal porcine thymus is uncoupled from somatic mutation. Vet. Immunol. Immunopathol., 87(3-4): 307319 . DOI: $10.1016 / \mathrm{S} 0165-$ 2427(02)00057-0

Butler JE, Zhao Y, Sinkora M, Wertz N, Kacskovics I. 2009. Immunoglobulins, antibody repertoire and B cell development. Dev. Comp. Immunol., 33(3): 321-333. DOI: http://dx.doi.org/10.1016/j.dci.2008.06. 015

Cabrera R, Lin X, Ashwell M, Moeser A, Odle J. 2013. Early postnatal kinetics of colostral immunoglobulin $\mathrm{G}$ absorption in fed and fasted piglets and developmental expression of the intestinal immunoglobulin $\mathrm{G}$ receptor.
J. Anim. Sci., 91(1): 211-218. DOI: 10.2527/jas.2011-4426

Carney-Hinkle EE, Tran H, Bundy WJ, Moreno R, Miller PS, Burkey TE. 2013. Effect of dam parity on litter performance, transfer of passive immunity, and progeny microbial ecology. J. Anim. Sci., 91(6): 28852893. DOI: $10.2527 /$ jas.2011-4874

Cervenak J, Kacskovics I. 2009. The neonatal Fc receptor plays a crucial role in the metabolism of $\mathrm{IgG}$ in livestock animals. Vet. Immunol. Immunopathol., 128(1-3): $\quad 171-177 . \quad$ DOI: 10.1016/j.vetimm.2008.10.300

Chabaudie N, Salmon H, Olivier M. 1987. Cinétique comparée d'apparition et d'évolution des différentes souspopulations lymphocytaires dans le sang et la glande mammaire de truie cyclique, gestante et allaitante. Jour. Rech. Porc., 19: 161-169.

Chabaudie N, Le Jan C, Olivier M, Salmon H. 1993. Lymphocyte subsets in the mammary gland of sows. Res.Vet.Sci., 55(3): 351-355. DOI: 10.1016/00345288(93)90106-P

Charley B, Corthier G. 1977. Local immunity in the pig respiratory tract. II. Relationship of serum and local antibodies. Ann. Microbiol., 128B(1): 109-119.

Corino C, Pastorelli G, Rosi F, Bontempo V, Rossi R. 2009. Effect of dietary conjugated linoleic acid supplementation in sows on performance and immunoglobulin concentration in piglets. J. Anim. Sci., 87(7): 2299-2305. DOI: 10.2527/jas.2008-1232

Csapo J, Martin GT, Csapo-Kiss ZS, Hazas Z, 1996. Protein, Fats, Vitamin and Mineral Concentrations in Porcine Colostrum and Milk from Parturition to 60 Days. Int. Dairy. J., 6(8-9): 88I-902. DOI: http://dx.doi.org/10.1016/09586946(95)00072-0 
Daudelin J-F. 2009. Détermination des effets de l'administration de probiotiques sur l'attachement d'Escherichia coli entérotoxinogène $\mathrm{F} 4$ et l'expression de cytokines chez le porcelet sevré. Mémoire de Maître ès Sciences ( $M$. Sc.), Faculté de Médecine Vétérinaire de l'Université de Montréal, Montréal, P. 105.

Decaluwé R, Maes D, Wuyts B, Cools A, Piepers S, Janssens GPJ. 2014. Piglets' colostrum intake associates with daily weight gain and survival until weaning. Livest. Sci., 162: 185-192. DOI: http://dx.doi.org/10.1016/j.livsci.2014.0 1.024

Declerck I, Dewulf J, Piepers S, Decaluwé R, Maes D. 2015. Sow and litter factors influencing colostrum yield and nutritional composition. J. Anim. Sci., 93(3): $\quad$ 1309-1317. DOI: 10.2527/jas.2014-8282

Devillers N, Le Dividich J, Prunier A. 2006. Physiologie de la production de colostrum chez la truie. INRA. Prod. Anim., 19 (1): 29-38.

Devillers N, Le Dividich J, Prunier A. 2011. Influence of colostrum intake on piglet survival and immunity. Anim., 5(10): 1605-1612.

DOI: https://doi.org/10.1017/S175173111100 067X

Drew DM, Owen DB. 1988. The provision of passive immunity to colostrum-deprived piglets by bovine or porcine serum immunoglobulins. Can. J. Anim. Sci., 68(4): $1277-1284$. DOI: $10.4141 /$ cjas88143

Eastwood L, Leterme P, Beaulieu AD. 2014. Changing the omega- 6 to omega- 3 fatty acid ratio in sow diets alters serum, colostrum, and milk fatty acid profiles, but has minimal impact on reproductive performance. J. Anim. Sci., 92(12): 5567-5582. DOI: $10.2527 /$ jas.20147836
Evans PA, Newby TJ, Stokes CR, Bourne FJ. 1982. A study of cells in the mammary secretions of sows. Vet. Immunol. Immunopathol., 3(5): 512-527. DOI: 10.1016/0165-2427(82)90017-4

Ferrari CV, Sbardella PE, Bernardi ML, Coutinho ML, Vaz JRIS, Wentz I, Bortolozzo FP. 2014. Effect of birth weight and colostrum intake on mortality and performance of piglets after cross-fostering in sows of different parities. Prev. Vet. Med., 114(3-4): 259266.

DOI:

http://dx.doi.org/10.1016/j.prevetmed.2 014.02 .013

Foisnet A, Farmer C, David C, Quesnel H. 2010a. Relationship between colostrum production by primiparous sows and sow physiology around parturition. $J$. Anim. Sci., 88(5): 1672-1683. DOI: 10.2527/jas.2009-2562

Foisnet A, Boulot S, Passet M, Farmer C, Quesnel H. 2010b. L'induction de la mise-bas affecte-t-elle la production de colostrum chez la truie? Jour. Rech. Porc., 42: 15-20.

Foisnet A, Farmer C, David C, Quesnel H. 2011. Farrowing induction induces transient alterations in prolactin concentrations and colostrum composition in primiparous sows. $J$. Anim. Sci., 89(10): 3048-3059. DOI: 10.2527/jas.2010-3507

Foubert C, Guyonvarch A, Mazerolles P, Marzin D, Legrand A. 2009. Amélioration du transfert d'immunité et de la survie des porcelets par une spécialité alimentaire. Jour. Rech. Porc., 41 : 1-x.

Geale FP. 2011. Characterisation of porcine colostrum and its impact on piglet growth. PhD Thesis, Sydney University, Sydney, p. 304.

Gin GTR. 2008. Diagnostic des nouveaux cas de diarrhées néonatales enzootiques du porcelet Evaluation de la prise colostrale. Thèse de Docteur 
Vétérinaire, Ecole Nationale Vétérinaire de Toulouse, Toulouse, p. 72.

Guillou D, Sacy A, Marchand D, Le Treut Y, Le Dividich J. 2012. Influence de l'apport alimentaire de Saccharomyces cerevisiae boulardii sur les immunoglobulines du colostrum et $\mathrm{du}$ lait de truie. Jour. Rech. Porc., 44: 189190.

Harada E, Itoh Y, Sitizyo K, Takeuchi T, Araki Y, Kitagawa H. 1999. Characteristic transport of lactoferrin from the intestinal lumen into the bile via the blood in piglets. Comp. Bioch. Physio., Part A: 124(3): 321-327. DOI: http://dx.doi.org/10.1016/S10956433(99)00122-1

Hiss-Pesch S, Daniel F, Dunkelberg-Denk S, Mielenz M, Sauerwein H. 2011. Transfer of maternal haptoglobin to suckling piglets. Vet. Immunol. Immunopathol., 144(1-2): 104-110. DOI: 10.1016/j.vetimm.2011.07.015

Hlavova K, Stepanova H, Faldyna M. 2014. The phenotype and activation status of $\mathrm{T}$ and NK cells in porcine colostrum suggest these are central/effector memory cells. The Vet. J., 202(3): 477482.

DOI: http://dx.doi.org/10.1016/j.tvj1.2014.09. 008

Hurley WL, THEIL PK. 2011. Perspectives on Immunoglobulins in Colostrum and Milk. Nutr., 3(4): 442-474. DOI: 10.3390/nu3040442

Klobasa F, Werhahn E, Butler JE. 1987. Composition of Sow Milk During Lactation. J. Anim. Sci., 64(5): 14581466. DOI: $10.2134 /$ jas $1987.6451458 \mathrm{x}$

Klopfenstein C, Couture Y, Martineau GP, Bouchard E. 2002. Physiopathologie comparative de la lactation chez la truie et chez la vache. Méd. Vét. Québec, 32: 52-56.

Krakowski L, Krzyzanowski J, Wrona Z, Kostro K, Siwicki AK. 2002. The influence of nonspecific immunostimulation of pregnant sows on the immunological value of colostrum. Vet. Immunol. Immunopathol., 87(1-2): 89-95.

DOI:

http://dx.doi.org/10.1016/S01652427(02)00004-1

Kunkel EJ, Butcher EC. 2003. Plasma-cell homing. Nat. Rev. Immunol., 3: 822829. DOI : $10.1038 /$ nri1203

Laws J, Amusquivar E, Laws A, Herrera E, Lean IJ, Dodds PF, Clarke L. 2009. Supplementation of sow diets with oil during gestation: Sow body condition, milk yield and milk composition. Livest. Sci., 123(1): 88-96. DOI: http://dx.doi.org/10.1016/j.livsci.2008.1 0.012

Le Dividich J, Herpin P, Paul E, Strullu F. 1997. Effect of Fat Content of Colostrum on Voluntary Colostrum Intake and Fat Utilization in Newborn Pigs. J. Anim. Sci., 75(3): 707-713. DOI: $10.2527 / 1997.753707 x$

Le Dividich J, Thomas F, Renoult H, Oswald I. 2005. Acquisition de l'immunité passive chez le porcelet : rôle de la quantité d'immunoglobulines ingérées et de la perméabilité intestinale. Jour. Rech. Porc., 37: 443-448.

Le Dividich J. 2006. Les enjeux du colostrum. Québec: Expo- Congrès du Porc, Québec, p. 72.

Lee CS, Mccauley I, Hartman PE. 1983. Light and Electron Microscopy of Cells in Pig Colostrum, Milk and Involution Secretion. Acta. Anat., 117(3): 270-280. DOI: $10.1159 / 000145798$

Lee SD, Kim JH, Jung HJ, Kim YH, Kim IC, Kim SB, Lim SY, Jung WS, Lee SH, Kim YJ. 2013. The effect of ginger extracts on the antioxidant capacity and $\mathrm{IgG}$ concentrations in the colostrum and plasma of neo-born piglets and sows. Livest. Sci., 154(1-3): 117-122. DOI: http://dx.doi.org/10.1016/j.livsci.2013.0 2.001 
Le Jan C, Chevaleyre C. 1996. Cellules épithéliales du colostrum de truie. Sensibilité au virus GET et propriétés in vitro. Jour. Rech. Porc., 28: 303-306.

Leonard GS, Sweeney T, Bahar B, Lynch PB, O'doherty VJ. 2010. Effect of maternal fish oil and seaweed extract supplementation on colostrum and milk composition, humoral immune response, and performance of suckled piglets. J. Anim. Sci., 88(9): 2988-2997. DOI: $10.2527 /$ jas.2009-2764

Levast B. 2010. Influence du lait maternel sur l'ontogenèse de la réponse immunitaire de l'intestin du porcelet. Thèse de doctorat, Université François Rabelais, Tours, p. 173

Loisel F, Farmer C, Ramaekers P, Quesnel H. 2013. Effects of high fiber intake during late pregnancy on sow physiology, colostrum production, and piglet performance. J. Anim. Sci., 91(11): $\quad 5269-5279 . \quad$ DOI: $10.2527 /$ jas.2013-6526

Loisel F, Farmer C, Ramaekers P, Quesnel H. 2014. Colostrum yield and piglet growth during lactation are related to gilt metabolic and hepatic status prepartum. J. Anim. Sci., 92(7): 29312941. DOI: $10.2527 /$ jas.2013-7472

Loisel F, Farmer C, Van Hees H, Quesnel H. 2015. Relative prolactin-toprogesterone concentrations around farrowing influence colostrum yield in primiparous sows. Dom. Anim. Endocrinol., 53: 35-41. DOI: http://dx.doi.org/10.1016/j.domaniend.2 015.04 .005

Lompo-Ouedraogo Z, Van Der Heide D, Van Der Beek EM, Swarts HJM, Mattheij JAM, Sawadogo L. 2004. Effect of aqueous extract of Acacia nilotica ssp adansonii on milk production and prolactin release in the rat. $J$. Endocrinol., 182: 257-266. DOI: 10.1677 joe. 0.1820257
Mateo DR, Carroll AJ, Hyun Y, Smith S, Kim WS. 2009. Effect of dietary supplementation of n-3 fatty acids and elevated concentrations of dietary protein on the performance of sows. $J$. Anim. Sci., 87(3): 948-959. DOI: 10.2527/jas.2008-0964

Mei J, Zhang Y, Wang T, Sangild PT, Xu RJ. 2006. Oral ingestion of colostrum alters intestinal transforming growth factor-beta receptor intensity in newborn pigs. Livest. Sci., 105(1-3): 214-222.

DOI: http://dx.doi.org/10.1016/j.livsci.2006.0 6.017

Murata H, Namioka S. 1977. The duration of colostral immunoglobulin uptake by the epithelium of the small intestine of neonatal piglets. J. Comp. Path., 87(3): 431-439. DOI: $\quad 10.1016 / 0021-$ 9975(77)90032-9 Get rights and content Nechvatalova K, Kudlackova H, Leva L, Babickova K, Faldyna M. 2011. Transfer of humoral and cell-mediated immunity via colostrum in pigs. Vet. Immunol. Immunopathol., 142(1-2): 95100.

DOI: http://dx.doi.org/10.1016/j.vetimm.2011 .03 .022

Nguyen VT, Yuan L, Azevedo SPM, Jeong K-I, Gonzalez A-M, Saif LJ. 2007. Transfer of maternal cytokines to suckling piglets: In vivo and in vitro models with implications for immunomodulation of neonatal immunity. Vet. Immunol. Immunopathol., 117(3-4): 236-248. DOI:

http://dx.doi.org/10.1016/j.vetimm.2007 .02 .013

Quesnel H. 2011a. Colostrum: roles in piglet performance and production by the sow. VI sinsui-Simposio internacional de suinocultura

Quesnel H. 2011b. Colostrum production by sow: variability of colostrum yield and immunoglobulin $\mathrm{G}$ concentrations. 
Anim., 5(10): 1546-1553. DOI: https://doi.org/10.1017/S175173111100 070X

Quesnel H, Farmer C, Theil PK. 2015. Colostrum and milk production. In The Gestating and Lactating Sow, Farmer C (ed). Wageningen Academic Publishers: Wageningen; 173-192

Reber JA, Donovan CD, Gabbard J, Galland $\mathrm{K}$, Aceves-Avila M, Holbert AK, Marshall L, Hurley DJ. 2008. Transfer of maternal colostral leukocytes promotes development of the neonatal immune system I. Effects on monocyte lineage cells. Vet. Immunol. Immunopathol., 123(3-4): 186-196. DOI:

http://dx.doi.org/10.1016/j.vetimm.2008 .01 .034

Rincheval-Alarnold A, Belair L, Djiane J. 2002. Developmental expression of pIgR gene in sheep mammary gland and hormonal regulation. J. Dairy Res., 69(1): 13-26. DOI: https://doi.org/10.1017/S002202990100 5362

Rooke AJ, Bland MI. 2002. The acquisition of passive immunity in the new-born piglet. Livest. Prod. Sci., 78(1): 13-23. DOI: http://dx.doi.org/10.1016/S03016226(02)00182-3

Rossi R, Pastorelli G, Bontempo V, Corino C. 2004. Effects of Dietary Conjugated Linoleic Acid (CLA) on Immunoglobulin Concentration in Sow Colostrum and Piglet Serum. Vet. Res. Com., 28(1): 241-244. DOI: 10.1023/B:VERC.0000045416.53861.6 6

Roux ME, McWilliams M, Phillip-Quagliata JM, Weisz-Carrington P, Lamm ME. 1977. Origin of IgA-secreting plasma cells in the mammary gland. J. Expe. Med., 146(5): 1311-1322. DOI: 10.1084/jem.146.5.1311
Rouze P. 1974. La réponse immunitaire du jeune porcelet. Jour. Rech. Porc., 1721.

Salmon H. 1984. Immunité chez le foetus et le nouveau-né : modèle porcin. Reprod. Nutr Dév., 24(2): 197-206.

Salmon H. 1987. The intestinal and mammary immune system in pigs. Vet. Immunol. Immunopathol., 17(1-4): 367 388.

DOI: http://dx.doi.org/10.1016/01652427(87)90155-3

Salmon H. 1999. The mammary gland and neonate mucosal immunity. Vet. Immunol. Immunopathol., 72(1-2): 143155.

DOI: http://dx.doi.org/10.1016/S01652427(99)00127-0

Salmon H, Berri M, Gerdts V, Meurens F. 2009. Humoral and cellular factors of maternal immunity in swine. Dev. Comp. Immunol., 33: 384-393. DOI: http://dx.doi.org/10.1016/j.dci.2008.07. 007

Salmon H, Berri M, Meurens F. 2010. Immunité maternelle colostrale et lactée : facteurs humoraux et cellulaires d'induction et de transmission au porcelet jusqu'au sevrage. Jour. Rech. Porc. 241.

Salmon H. 2011. Transmission de l'immunité maternelle chez le porc et les ruminants après la naissance. Bull. Acad. Vét. France., 164(3): 203-210.

Sawadogo L. 1987. Contribution à l'étude des plantes médicinales et de la pharmacopée traditionnelle africaine : cas des plantes lactogènes. Thèse de Doctorat d'Etat des Sciences Naturelles, Université François-Rabelais, Tours.

Schnulle PM, Hurley WL. 2003. Sequence and expression of the FcRn in the porcine mammary gland. Vet. Immunol. Immunopathol., 91(3-4): 227-231. DOI: http://dx.doi.org/10.1016/S01652427(02)00294-5 
Sepehri H, Kann G, Houdebine L-M. 1992. Pouvoir lactogène potentiel de quelques extraits de plantes iraniennes. Cah. Agri., 1: 35-39.

Shen YB, Carroll JA, Yoon I, Mateo RD, Kim SW. 2011. Effects of supplementing Saccharomyces cerevisiae fermentation product in sow diets on performance of sows and nursing piglets. J. Anim. Sci., 89(8): 2462-2471. DOI: $10.2527 /$ jas.20103642

Simister NE, Rees AR. 1985. Isolation and characterization of an $\mathrm{Fc}$ receptor from neonatal rat small intestine. Eur. J.Immunol., 15(7): 733-738. DOI: 10.1002/eji.1830150718

Sinkora J, Rehakova Z, Sinkora M, Cukrowska B, Tlaskalova-Hogenova $\mathrm{H}$. 2002. Early development of immune system in pigs. Vet. Immunol. Immunopathol., 87(3-4): 301-306. DOI: http://dx.doi.org/10.1016/S01652427(02)00056-9

Stirling CMA, Charleston B, Takamatsu H, Claypool S, Lencer W, Blumberg RS, Wileman TE. 2005. Characterization of the porcine neonatal $\mathrm{Fc}$ receptorpotential use for trans-epithelial protein delivery. Immunol., 114(4): 542-553. DOI: $10.1111 / \mathrm{j} .1365-$ 2567.2004.02121.x

Svendsen J, Weström BR, Olsson A-Ch, Svendsen LS, Karlsson BW. 1990. Environmental and husbandry factors affecting the acquisition of passive immunity in the suckling pig. World Rev. Anim. Prod., 25(4): 11-19.

Wolinski J, Biernat M, Guilloteau P, Weström B, Zabielski R. 2003.
Exogenous leptin controls the development of the small intestine in neonatal piglets. J. Endocrinol., 177: 215-222. DOI: 10.1677/joe.0.1770215

Wu WZ, Wang XQ, Wu GY, Kim SW, Chen F, Wang JJ. 2010. Differential composition of proteomes in sow colostrum and milk from anterior and posterior mammary glands. J. Anim. Sci., 88(8): 2657-2664. DOI: 10.2527/jas.2010-2972

Wuryastuti H, Stowe HD, Bull RW, Miller ER. 1993. Effects of vitamin $E$ and selenium on immune responses of peripheral blood, colostrum, and milk leukocytes of sows. J. Anim. Sci., 71(9): 2464-2472.

DOI: 10.2527/1993.7192464x

Xu R-J, Wang T. 1996. Gastrointestinal Absorption of Insulinlike Growth Factor-I in Neonatal Pigs. J. Pediat. Gastroenterol. Nutr., 23(4): 430-437.

Xu RJ, Sangild PT, Zhang YQ, Zhang SH. 2002. Bioactive compounds in porcin colostrum and milk and their effects on intestinal development in neonatal pigs. In Biology of the Intestine in Growing Animals, Zabielski R, Gregory PC, Weström B, Salek E (eds). Amsterdam; 169-192.

Zanello G, Meurens F, Serreau D, Chevaleyre C, Melo S, Berri M, D'Inca R, Auclair E, Salmon H. 2013. Effects of dietary yeast strains on immunoglobulin in colostrum and milk of sows. Vet. Immunol. Immunopathol., 152(1-2): 20-27. DOI: http://dx.doi.org/10.1016/j.vetimm.2012 .09 .023 . 